\title{
Género y cuerpo en la educación sexual en el nivel de secundaria en Barranquilla'
}

\author{
Ligia Cantillo Barrios² \\ Universidad del Atlántico
}

Artículo de Investigación

Recibido: abril 16 de 2015 - Aprobado mayo 27 de 2015

\section{Resumen}

El objetivo de este trabajo es identificar la situación de la educación sexual impartida en los niveles de secundaria en las escuelas del distrito de Barranquilla. Para ello, se utilizó el método descriptivo, cualicuantitativo con enfoque etnográfico. Se aplicaron I50 encuestas a estudiantes que hicieron posible poder observar que la educación sexual impartida en las escuelas tiene un enfoque biomédico, y tradicional, centrándose en el control natal, infecciones de trasmisión sexual, órganos reproductivos y cambios corporales. Dicho enfoque no incluye avances normativos y teóricos que separan sexualidad y reproducción.

Palabras claves: Educación sexual, género, cuerpo, sexualidad, escuela y estudiantes, Derechos humanos.

I Este artículo es un avance de la investigación en curso: Caracterización situacional de la educación sexual impartida en los niveles de secundaria en los centros educativos del distrito de Barranquilla. Se inició en febrero y finalizará en noviembre 20I5. Carece de financiación, es asumida por la misma autora.

2 Socióloga, Especialista en Género Planeación y Desarrollo; Maestría en Estudios Políticos y Económicos. Docente- investigadora, Integrante del Grupo de Investigación: Mujer, Género y Cultura. Universidad del Atlántico, Barranquilla, Colombia. Publicaciones: Género y carnaval en Barranquilla", publicado en la Revista Amauta Número 24 de julio a diciembre del 20 I4. "Tradición cultural y familia afrodescendiente en Barranquilla", publicado en la Revista Amauta Número 24 de julio a diciembre del 20 I 3. La población lesbianas, gays, travestis, bisexuales e intersexuales (LGTBI) en el departamento del Atlántico, Publicado en la Revista la Manzana de la Discordia de la Universidad del Valle, enero-junio 20 I3. Vol. 8 No. I. Coautora Barranquilla con mirada femenina, Construcción de las Políticas Públicas de Mujeres en Barranquilla para el fortalecimiento de la Red del Buen Trato (20 I I); Las Juntas de Acción comunal del Distrito de Barranquilla y el Fortalecimiento de la Participación de las Juntas de Acción Comunal de la Localidad Suroccidente (20 I I); coautora Diagnóstico de las Políticas Públicas de las Mujeres en la ciudad de Barranquilla para el fortalecimiento de la Red del Buen Trato. 2009. Dirección electrónica: ligiacantillo@mail.uniatlantico.edu.co / ligiaesther@yahoo.com. 


\title{
Gender and body in sex education at the level of secondary school in Barranquilla
}

\begin{abstract}
The objective of this study is to identify the situation of sex education provided at the secondary school level in the district of Barranquilla. To do this, a descriptive, quali-quantitative method was used with an ethnographic approach. I 50 surveys were applied to students who made it possible to observe that the sexual education in schools has a biomedical approach, traditional, focusing on birth control, infections, sexually transmitted, reproductive organs and bodily changes. Such an approach does not include normative and theoretical advances that separate sexuality and reproduction.
\end{abstract}

Key words: sex education, gender, body, sexuality, school, students, Human rights.

\section{Gênero e corpo na educação sexual no nível de ensino médio em Barranquilla.}

\section{Resumo}

O objetivo deste estudo é identificar a situação dos níveis de educação sexual de escolas secundárias do distrito de Barranquilla. Para isso, utilizou-se o método descritivo, cualicuantitativo com abordagem etnográfica. I 50 inquéritos foram aplicados aos alunos que foi possível observar que a educação sexual nas escolas tem uma abordagem biomédica, tradicional, com foco em controle de natalidade, infecções, sexualmente transmissíveis, órgãos reprodutivos e alterações corporais. Tal abordagem não inclui avanços teóricos e normativos que separam sexualidade e reprodução.

Palavras chave: educacion sexual, gênero, corpo, sexualidade, escola, estudantes, direitos humanos.

\section{Introducción}

Las relaciones de género como categoría social presentan mayor relevancia en la actualidad debido a las altas cifras de las violencias de género, las cuales se manifiestan a través de la violencia intrafamiliar que suele terminar en feminicidios. Igualmente, alarma la violencia que se genera en los centros educativos, conocida como acoso escolar o bullying. Este hecho coloca en situación de riesgo a la comunidad estudiantil y, en particular, a quienes demuestran algún tipo de diferencias distintas a las que predomina como "normales" y en especial, a quienes tienen identidades de género y de sexualidad diferentes a las heterosexuales.

Las distintas formas de violencias que se expresan en la vida cotidiana se anidan en el cuerpo como territorio, en el cual se transversaliza todo el hacer y pensar del mundo de la vida. Una de ellas es la sexualidad, la cual forma parte del control social. No solo es cualidad humana, es una necesidad 
de la forma predominante que garantiza la reproducción de la especie humana. También incluye el encuentro y reencuentro del placer erótico y/o afectivo.

De esta manera, la escuela como espacio socializante es clave para el acondicionamiento social de hombres y mujeres. A través de este proceso a las personas se les trasmiten los conocimientos objetivos y subjetivos del mundo de la vida, requeridos para que actúen en "forma normal" en la vida cotidiana y laboral según lo estipulado por la sociedad.

Desde esta perspectiva la escuela, en su labor socializante, es la indicada para preparar a las nuevas generaciones que la sociedad requiere para mantener su status quo. Entre esas transferencias de conocimiento está la educación sexual a la población estudiantil en todos sus niveles, en razón a que se asume que los seres humanos son sexuados y que igualmente, la sexualidad es un derecho humano. Por tanto, para que las personas la disfruten integralmente sin ningún riesgo, requieren de una orientación profesional y confiable para que ese derecho, que al mismo tiempo, es un deber, sea asumido con responsabilidad personal y social.

Sin embargo, la escuela como producto social y al mismo tiempo, institución socializante no es ajena a las cargas tradicionales de la impronta de la cultura patriarcal y judeocristiana que imperan en el medio. La escuela utiliza como vehículo para la trasmisión del conocimiento al currículo explícito y/u oculto. El primero, es los conjuntos de actividades, contenidos y objetivos que se proyectan para el logro de fines específicos. Mientras que el segundo, no está explicito, y por tanto, no es abiertamente intencional y por ello, encubre una forma de establecer el acondicionamiento social.

En este sentido, la escuela en su función socializante no es una institución neutral. Su misma configuración, organización y funcionamiento están regidos por los patrones impuestos por las estructuras de poder social, económico y cultural vigentes.

\section{Identidad de Género}

La identidad insinúa un sentido de pertenencia en un conglomerado social específico con el cual se comparten rasgos identitarios comunes. Por tanto, la identidad de género expresa las varias formas de masculinidad y de feminidad que realizan, sienten y con las cuales suelen identificarse las persona durante su vida. Mientras que las identidades sexuales refieren al interés que expresan hombres y mujeres de su opción sexual, ya sea heterosexual, homosexual o bisexual.

El concepto de género es un constructo cultural de bipolarización social. De esta manera, la construcción sociocultural del género parece responder a esa lógica bipolarizada y jerarquizada que establece espacios diferentes para hombres y mujeres. Esta relación se conecta con el sistema ideológico del patriarcado y judeocristiana, las cuales se manifiestan en forma androcéntrica y por tanto excluyente. 
Esto hace posible que la dominación masculina imponga unos roles tradicionales específicos para hombres y mujeres. Los primeros inscritos en el espacio público y el poder; los segundos, en el ámbito privado y la ética del autocuidado. De tal suerte que los roles de unos y otras están inscritos y se orientan en formas y modos de hacer, pensar distintos en la cotidianidad.

Igualmente, esta dominación masculina y androcéntrica determina una sexualidad heterocentrada, falocéntrica, penetrativa y reproductiva como modelo único para la realización de lo erótico afectivo. De esta forma, lo que esté por fuera de estos parámetros es "anormal" y por ello, estigmatizado y excluido socialmente, dando lugar a las distintas fobias.

Desde esta perspectiva, tanto la masculinidad como la feminidad a la luz del patriarcado están determinados por una preeminencia de rasgos establecidos como masculinos y femeninos e igualmente, una práctica sexual, es decir, heterosexuales. Ser hombre en esta representación se identifica ante todo por la negación a no ser una mujer y, al mismo tiempo, no ser un homosexual. En este sentido, tanto lo femenino como lo homosexual se asumen con cierta desvalorización por la tradición patriarcal. Mientras que lo masculino se sobrevalora y por ello, es importante.

Esto determina que ser hombre es mostrar preferencias en lo erótico afectivo por una mujer. A la par, que la mujer debe tener como pareja sexual al hombre. No ser homosexual es ya una garantía de "normalidad" tanto de masculinidad como de feminidad en la concepción tradicional de la dominación androcéntrica.

A pesar de todo, con el tiempo se ha demostrado que muchos roles asignados a determinados géneros no son exclusivos de un sexo, sino que pueden ser desempeñados de igual forma por ambos, sin trasgredir, ni desconocer la identidad sexual y las diversas formas como las mismas pueden asumirse y manifestarse.

En este sentido, Robert Stoller ${ }^{3}$, manifiesta que preexiste una identidad de género nuclear unitaria que se constituye en la infancia por la interacción emocional entre los progenitores y los descendientes. Sus investigaciones se realizan con transexuales a quienes les reasignaron la identidad de género nuclear a través de la cirugía, argumentado que "no es el deseo de tener tal identidad sino la convicción de ser tal"

\section{Cuerpo}

El cuerpo encierra al ser humano; es su producto y al mismo tiempo, es un producto construido socialmente. A través de él se identifican las cualidades y especificidades de lo que es, siente y expresa en su intimidad, en el entorno y con sus construcciones socioculturales.

3 Stoller, Roberto citado Connel, Robert, W. "Masculinidades". Programa Universitario de Estudios de Género. México Universidad Autónoma de México. 2003, pág. 31. 
En este sentido, el cuerpo como producto integrador del ser, trasciende todas las dimensiones socioculturales del mundo de la vida. Además, con sus significados y significantes que le dan uso, valor, sentido en un contexto tanto espacial como temporal. Ello vinculado a la diferenciación de clase social, género, edad, diversidad funcional (discapacidad) y etnia.

Pierre Bourdieu ${ }^{4}$ afirma: "El mundo es comprensible, está inmediatamente dotado de sentido, porque el cuerpo, que gracias a sus sentidos y su cerebro tiene capacidad de estar presente fuera de sí, en el mundo (...) Aprendemos por el cuerpo, el orden social se inscribe en los cuerpos a través de esta confrontación permanente". Al mismo tiempo, David Le Breton ${ }^{5}$ manifiesta, "Del cuerpo nace y se propagan las significaciones que constituyen la base de la existencia individual y colectiva. Es el eje de la relación con el mundo, el lugar y el tiempo en el que la existencia se vuelve carne a través de la mirada singular de un actor".

En esta dirección, el cuerpo inserto en la sociedad y como producto de ella, cruza todas las instancias del entramado sociocultural, afectivo y de todas las manifestaciones posibles del ser y sentir humano. Es el territorio en el cual se instalan las expresiones de la sublimidad humana con todas sus cosmovisiones pasadas y presentes.

\section{Sexualidad}

La sexualidad es una construcción social dinámica. Se produce en relación con los esquemas cognitivos históricos y culturales, no solo de tiempo espacio, sino también de la ética ciudadana y de las estructuras sociales, económicas, políticas, parentales, religiosas, géneros y jurídicas. Además, con lo biológico, psicológico y el sexo en todos los ciclos vitales de la vida humana. Igualmente, es una necesidad biológica y de control social que incluye el poder. Mercedes Lagarde ${ }^{6}$ y Foucault ${ }^{7}$ afirman que la sexualidad se ubica en la base del poder y de control social

También la sexualidad se produce en relación con los parámetros epistémicos de cada coyuntura sociohistórica y cultural. Además, se inscribe en unas relaciones temporales y espaciales. Está conectada con las simbologías de usos, valores, costumbres y rituales. De esta manera, se arman sus distintas formas de hacer, sentir y expresar.

Igualmente, la sexualidad se articula con visiones biológicas, psicológicas, culturales y sociales. También, con características anatómicas, fisiológicas, deseos, emociones, expectativas, afectivas, conductuales y ambientales relacionadas con el sexo. Estas cruzan el cuerpo de modo y formas decisivas en todos sus ciclos vitales independiente de la clase, género, etnia y edad pero a la par marca su impronta en las personas en relación con ello.

\footnotetext{
$4 \quad$ Bourdieu, Pierre Meditaciones pascalianas. Barcelona: Anagrama. 1999, págs. I 80 y 186.

5 Le Breton, David. La sociología del cuerpo., Buenos Aires: Ediciones Nueva Visión, 2002, págs. 7 y 8.

6 Lagarde, Marcela. El cautiverio de las mujeres: madreesposa, monjas y locas. México: UNAM, 2003, pág. 184.

7 Foucault, Michel. Historia de la sexualidad I voluntad del saber. Trigésima edición. Buenos Aires, Argentina: Siglo XXI. 2005.
} 
La sexualidad es una necesidad biológica pero instalada en una construcción social de tiempo y espacio y por tanto, de control social y que incluye el poder. Marcela Lagarde, afirma: "En la historia de la evolución humana, la sexualidad aparece como uno de los ejes de la configuración de la cultura, (...) En sociedades como la nuestra, la sexualidad está presente en todos los ámbitos de la vida y es el fundamento de muchos de ellos. (...) la sexualidad es elemento organizador y núcleo de la identidad de grupos que se constituyen en torno suyo, como los géneros, y de la autoidentidad de cada individuo.

\section{Educación sexual}

La escuela es uno de los lugares por excelencia para la socialización. Está legitimada para la trasmisión de conocimientos a las nuevas generaciones. En ella se aplican sucesos para la constitución de la subjetividad de la comunidad estudiantil. Se asume que debe ser un espacio generador de equidad de oportunidades, posibilidades y opciones que potencializan el desarrollo individual y colectivo. Además, allí permanece gran parte del día durante el mayor lapso del año. Aquí también transcurren las transformaciones del ciclo de la pubertad a la adolescencia, etapas éstas donde tienen lugar las trasformaciones físicas y mentales

No obstante, la escuela pese a su función de formar para la equidad, presenta experiencias inequitativas contextualizadas en relación con las desigualdades de clase, género, etnia y edad. Estas se observan y propagan con el currículo, en particular el oculto, a través de mensajes, imágenes, expectativas, estímulos y sanciones diferenciales de acuerdo con la manera como cada persona se ubica en su contexto socioeconómico, cultural espacial y temporal.

Para superar estas desigualdades presentes en la educación, se promovió la apertura educativa y la coeducación en las escuelas, para permitir el ingreso de la mayoría poblacional al sistema de educación formal de una manera más equitativa, tanto de clase, género y etnia. Este hecho ha generado resultados positivos pero aún permean al currículo explícito y al oculto los rezagos que sitúan en forma diferencial a cada persona, de acuerdo con dichas diferencias y en particular, el sexismo que es una de las claves que definen la sociedad patriarcal.

Esto se evidencia en la educación sexual cuando en el currículo oculto prevalecen todavía los estereotipos de los roles tradicionales de género, aunque desde finales de la década de los 70s, con el surgimiento del feminismo y del postestructuralismo se ubicó la categoría de género en el centro de los análisis del currículum oculto y más aún de la educación sexual.

La educación sexual se manifiesta como una instancia de delimitación identitaria con el fin de regular un conjunto de prácticas pedagógicas en la cual se ubica a la población estudiantil como sujetos claves del proceso educativo. De esta forma, en Colombia en la década de los sesenta, como una estrategia del control natal se inició en las escuelas las cátedras de Ciencias Naturales y Salud o

8 Lagarde, Op. Cit., pág. 185. 
de Comportamiento y Salud. Igualmente, en los 80s el Ministerio de Educación (MEN) editó unos manuales pedagógicos sobre sexualidad con el auspicio del Fondo de Población de las Naciones Unidas (UNFPA). También, en la década de los 90s a través de la Constitución de 1991 se incluyeron los Derechos Sexuales y Reproductivos como derechos fundamentales, lo cual contextualiza al país con el tema. Además, en el fallo de la Corte Constitucional en 1993 se estableció la necesidad de incluir la educación sexual en el país. Esta implica la obligatoriedad de la educación sexual en los centros educativos. El Ministerio de Educación Nacional con la Resolución 3353 de 1993 fundamentó el Proyecto Nacional de Educación Sexual (PNES). De manera equivalente, la Ley General de Educación (Ley II 5 de 1994) en el Artículo I4, literal e, ratificó la obligatoriedad de la educación sexual, "impartida en cada caso de acuerdo con las necesidades psíquicas, físicas y afectivas de los educandos según su edad".

En 2003, el gobierno nacional, con el apoyo del Fondo de Población de las Naciones Unidas y a través del Ministerio de la Protección Social, que integra los sectores de salud y trabajo, hizo pública la Política Nacional de Salud Sexual y Reproductiva. Se implementó la formulación conceptual y operativa del Proyecto de Educación para la Sexualidad y la Construcción de Ciudadanía (PESCC), que corresponde a una propuesta de educación formal en preescolar, básica y media, con el enfoque de construcción de ciudadanía y ejercicio de los derechos humanos, sexuales y reproductivos.

Así mismo, en 2007 el Plan Nacional Decenal de Educación 2006-20I5 (PNDE), adoptado en asamblea general propende por la promoción de la educación para la sexualidad desde un enfoque de derechos. Es definir la sexualidad como derecho humano separada de lo productivo y reconociéndola sin sesgos de los roles tradicionales masculinos, femeninos y de la orientación sexual. Es el respeto por la diversidad y la inclusión sexual desde la escuela.

Las disposiciones actuales sobre el sistema educativo en el país, también están amparadas por la Ley 1098 de 2006, o la Ley de la Infancia y la Adolescencia, en la cual se reconoce a la niñez y la adolescencia como sujetos titulares de derechos. Estos derechos están consagrados en la Convención Internacional de los Derechos del Niño (1989).

En 2010 la Oficina de la Organización de las Naciones Unidas, la Ciencia y la Cultura (Unesco) elaboró el proyecto "Orientaciones técnicas internacionales sobre educación en sexualidad". Esta tiene como objetivo promover en la comunidad educativa la autorresponsabilidad de "sus propios actos" y comportamientos y el reconocimiento de la otredad en la inclusión. También, En 2010 en Barranquilla, el Plan Distrital Decenal de Educación 2010 - 2020, plantea la educación de calidad con inclusión social y sin discriminación de ningún tipo.

Es decir, que en el país se han venido diseñando las estrategias normativas para generar procesos pedagógicos para la inclusión de la educación sexual en la escuela de manera coherente, reflexiva y formativa desde el compromiso que tiene la escuela en la formación de sus nuevas generaciones acorde con cada momento histórico. 
De esta manera, desde la normativa jurídica, en el país están creadas las condiciones para educar en la diversidad. Se han generado los espacios y debates necesarios para que la población estudiantil reciba una educación sexual en el contexto de los derechos humanos, sexuales y reproductivos, considerados estos como los más humanos de los derechos al separar la sexualidad de la reproducción. En este sentido, esta formación debe impartirse a todas y todos, sin discriminaciones de ningún tipo, como factor clave para el desarrollo integral humano de las nuevas generaciones.

\section{Metodología}

Este artículo es un avance de la investigación en curso "Caracterización situacional de la educación sexual impartida en los niveles de secundaria en los centros educativos del distrito de Barranquilla". Este es una provocación para identificar la situación de la educación sexual en las escuelas de esta ciudad.

En el estudio se aplicó el método descriptivo y cualicuantitativo con un enfoque etnográfico, como estrategia para describir, analizar y visibilizar las manifestaciones que ellos y ellas tienen sobre las enseñanzas que reciben sobre educación sexual y el cuerpo desde una mirada de género. Se utilizó como fuente teórica y metodológica la revisión bibliográfica y las encuestas. Para estos resultados se han encuestado 150 estudiantes de secundaria de diferentes niveles, centros educativos y de calendarios A y B; edad, estratos socioeconómicos, etnias y género residentes en Barranquilla. Esta muestra fue tomada aleatoriamente y se preguntó: ¿Está cursando el nivel de secundaria? y su respuesta era sí. Las personas se mostraban amables al responder, algunas, tanto hombres como mujeres, eran extrovertidas en las respuestas, otras, pocas, se mostraban tímidas, lo cual se observaba cuando bajaban la cabeza y una sonrisa tímida que exteriorizaba el tabú que aún produce hablar en público sobre sexualidad.

De esta forma, se armó y contextualizó las preguntas problemas: ¿Cuál es la percepción que tiene la población estudiantil del nivel de secundaria de la información que reciben sobre educación sexual y el cuerpo desde una mirada de género en algunas escuelas en la ciudad de Barranquilla?, ¿La información que reciben está o no en relación con lo estipulado por la normativa jurídica y el momento histórico? y ¿Se establece o no alguna diferencia de género en la información recibida?

\section{Resultados}

La Educación en Barranquilla está regulada por la Secretaría de Educación, dependencia de la Alcaldía Distrital, adscrita al Ministerio de Educación Nacional, MEN. Esta se divide en pública y privada y se ofrece en calendario A y B, en el calendario B solo se inscribe algunas escuelas privadas, en su mayoría perteneciente al estrato alto. Los resultados de las pruebas saberes no señalan buenos resultados de educación secundaria en general, sin embargo, últimamente se muestran mejorías. Según la oficina 
de Planeación Departamental de la gobernación del Atlántico9, en el 2013, no se consiguió la del 2014, existen matriculados en los centros educativos del distrito I I I.283 estudiantes en los niveles de 6 a II grados, distribuidos en los calendarios A y B y distribuidos por sexos: mujeres $50.7 \%$ y hombres $49.2 \%$.

Las 150 encuestas se aplicaron a estudiantes que residen en la ciudad de Barranquilla de diferentes sexo, nivel de escolaridad, edad, estratificación socioeconómica, adscritos al sector público y privado de educación, del calendario A y B y tendencia religiosa. Esto con el fin tener una caracterización generalizada de la población objeto de estudio, la cual corresponda con las características de la población estudiantil del nivel de secundaria del Distrito.

Desde esta perspectiva, la población en estudio se discriminan por sexo, 50.6\% mujeres y $49.4 \%$ hombres. Esto permite adquirir una visión equitativa de género a partir de la información recogida.

Particularmente, esta población se ubica en los niveles escolares así: 30.6\% de 6 a 7 grado, 38. 1\% de 8 a 9 grado y $31.3 \%$ de 10 a 1 I grado. Los porcentajes por niveles muestran cierta similitud numérica, lo cual indica que la representación por niveles es similar para garantizar la equidad de los resultados según la manera como los y las estudiantes percibe y manifiesta la información que reciben según su ciclo escolar.

La distribución por edades del grupo de estudio se distribuye así: 17.3\% de II a 12 años; 29.3\% 13 a 14 años; $32.6 \%$ de 15 a 16 años; $19.3 \%$ de 17 a 18 años y $0.1 \%$ más de 18 años. Los datos de edad señalan que el ciclo secundario y la educación media la realizan en el promedio de edad de los II a I 8 años. La presencia de la extra edad es escasa. Lo cual indica que esta población cursa y culmina este período académico en el tiempo que se considera pertinente para ello. Es decir, que esta etapa coincide con el ciclo de vida que corresponde a la pubertad y la adolescencia.

La población encuestada según los resultados de las encuestas pertenece a todos los estratos socioeconómicos ( I al 6), en los cuales según la Secretaria de Planeación Distrital se divide Barranquilla. El grupo objeto de estudio se encuentra ubicado porcentualmente en los siguientes estratos: $36.6 \%$ corresponde al estrato I y 2; $56.6 \%$ al estrato 3 y 4 y $6.6 \%$ se ubica en el estrato 5 y 6 . Es decir, que la población encuestada corresponde a la estratificación social de la ciudad, ubicándose el mayor porcentaje en la franja que aglutina la mayoría del conglomerado de la estratificación social I y 3 con el $66.0 \%$. Ello permite tener una visión ampliada de cómo se maneja el tema de educación sexual de acuerdo con la estratificación socioeconómica de la comunidad en estudio.

Por su parte, el grupo encuestado que pertenece al sector educativo público es $54.7 \%$ y el sector privado 45.3\%. Se observan diferencias entre la educación pública y privada, aunque no tan marcadas, lo cual genera relación con la distribución porcentual de estratificación social en los cuales el estrato del 4 y 6 representa el 34\% e, incluso el estrato 3 (29.3\%), estos tienen mayor acceso a la educación privada. No obstante, el $66.0 \%$ está en los estratos más bajos (I-3).

9 Información entregada por un funcionario de esa misma Oficina, enero 20 I5, se omite su nombre a solicitud del interesado. 
En cuanto a la tendencia ideología religiosa de los centros educativos donde estudia la población encuestada el 77.3\% pertenecen a la religión católica; 10.6\% están congregados a la iglesia cristiana y $12.0 \%$ en otros tipos de iglesia que dirigen la educación formal en la ciudad o a las que no tiene institucionalmente ningún tipo de religión. Los datos señalan la marcada relación entre la educación con la religiosidad, y en particular, la católica en las escuelas del Distrito.

Esta caracterización diversa en cuanto a nivel educativo, edad, sexo, estratificación social, educación pública y privada, calendario A y B y la tendencia religiosa incide en los enfoques, contenidos, métodos, capacidades docentes y estrategias pedagógicas que se utilizan en cada escuela del distrito de Barranquilla para impartir la educación sexual a sus educandos. Es decir, que esta formación no es equitativa para toda la población estudiantil y por tanto, varía de unos a otras con sus respetivos efectos positivos o negativos.

Por otra parte, a la pregunta, ¿usted recibe formación sobre educación sexual en su escuela?, el 68.0\% de estudiantes respondió que sí y mientras que el 32.0\% respondió que no. Los datos señalan que es mayor la población a la cual se le imparte educación sexual que la que no la recibe. Esta información es recordada por la mayoría de las personas pero otras, manifiestan no recordar nada. Este hecho se presenta tanto en los hombres como en las mujeres de diferentes edades y niveles.

La respuesta a la pregunta, ¿La información que reciben sobre educación sexual está relacionada con un programa específico del pensum académico u obedece a un plan pedagógico del colegio? Su respuesta era no. El tema, según sus respuestas, se aborda ocasionalmente, tanto por personal interno como externo de la institución. El primero se puede derivar de las asignaturas de biología, ética y afectividad, entre otras. También, el área de psicorientación puede abordarlo algunas veces. En el segundo, se incluyen estudiantes universitarios, psicólogas, Profamilia, entre otros, a los cuales se les invita o llegan a la institución ofreciendo el servicio. Ambos grupos utilizan como estrategias pedagógicas, la cátedra magistral, talleres, videos y otros. Estas suelen estar acompañadas de la entrega de anticonceptivos. En particular, a los hombres se entregan los condones y se les explica cómo usarlos.

La respuesta a la pregunta, ¿Cuáles son los temas que se abordan sobre educación sexual?. Las respuestas eran que los temas que generalmente se abordan tienen que ver con el control prenatal, las infecciones de trasmisión sexual (ITS), sistema reproductivo y los ciclos humanos del cuerpo, asumidos desde la diferencia de macho y hembra, es decir, lo biológico y reproductivo. Todos estas temáticas transversalizadas por la ausencia de relaciones sexuales a temprana edad.

En este sentido, las relaciones sexuales se presentan como un "peligro" porque son las causantes del embarazo a temprana edad o no deseado con todas sus consecuencias y las infecciones de trasmisión sexual, del VIH/SIDA, la gonorrea y las otras, con sus respectivas consecuencias. Ante este peligro, se plantea por una parte, evitar las relaciones sexuales a temprana edad (abstinencia) y el otro, uso de métodos anticonceptivos (preservativos, pastillas e inyecciones y las demás). El "peligro" 
se refirma más en las mujeres porque son quiénes se embarazan y se les trunca la vida. En palabras de una estudiante ${ }^{10}$ de 14 años, "El embarazo arruina la vida".

Otro tema que causa interés es el funcionamiento de sistema reproductivo y los cambios de las etapas del cuerpo tanto de hombres como de mujeres. En la actualidad, se incluye el peligro del mal uso de las redes sociales. Todo ello tiene la intención de prevenirlos sobre los acechos perversos que pueden truncar sus proyectos de vida con perspectivas positivas.

Los datos anteriores, basados en los resultados de las encuestas, señalan que en la educación sexual y el cuerpo sigue vigente el enfoque tradicional de género (masculino y femenino) y bio-médico. La sexualidad y el cuerpo operan en un proceso de biologización, hacen de los órganos genitales y el sistema reproductivo de hombres y mujeres lo único válido y de legitimación de la sexualidad, la identidad y los cuerpos en el espacio de interrelación humana. En este sentido, Beatriz Preciado"I señala: la "tecnología sexual que identifica los órganos reproductivos como órganos sexuales, en detrimento de una sexualidad de la totalidad del cuerpo".

Es marcada la visión biologista y medicalizada, de la educación sexual en la escuela. El tema tiene en la "prevención", dos centros de atención especial: Uno el control prenatal y dos, las infecciones de transmisión sexual, básicamente para niñas y varones heterosexuales. Aquí, no se incluye la diversidad sexual. Evitar el embarazo es todavía una responsabilidad y un deber de las mujeres. Mientras a ellos, se les enseña cómo usar el condón, para evitar el embarazo y las infecciones de trasmisión sexual pero alejada de la paternidad responsable. De esta manera, con la responsabilidad de las mujeres se le garantiza la sexualidad hombre pero desligado de cualquier compromiso. Este aprendizaje en la escuela se contradice cuando desde niña a la mujer se le socializa el embarazo como destino necesario de su sexualidad femenina, pero al mismo tiempo, se le construye como "patología peligrosa" cuando se da en la adolescencia. Esta afirma una estudiante 12: "Tener relaciones sexuales es un riesgo, porque se embarazan y no se está preparada para cuidar bebe, siendo aún unas niñas". A la par que para los hombres la responsabilidad de la paternidad no está dada en el cuidado del bebe, tal como lo manifiesta un estudiante ${ }^{13}$ : "Hay que tener proyectos de vida para no meter las patas". Para la primera, la prevención es "no estar preparada para cuidar bebe" y para el segundo, "no meter las patas".

Igualmente, el cuerpo, como parte del sistema reproductivo, es considerado básicamente en dos dimensiones: Una, higienista y otra, religiosa. En la primera, el cuerpo se asume como un ente compuesto de partes delicadas y requieren del cuidado de los órganos sexuales a los cuales hay que proteger y evitar que nadie los toque. La segunda, el cuerpo como templo de Dios, hay que hacerlo respetar y valorar, más para la mujer. Una estudiante ${ }^{14}$ alega: "Nos dicen que el cuerpo hay que

I0 Encuesta realiza a un estudiante de 14 años, en la ciudad de Barranquilla, febrero 2015.

I I Preciado, Beatriz. Manifiesto contrasexual. Barcelona: Amagrama, 20 I I, pág. $15 .$.

I2 Encuesta realiza a una estudiante de 15 años, en la ciudad de Barranquilla, febrero 2015.

13 Encuesta realiza a un estudiante de 16 años, en la ciudad de Barranquilla, febrero 2015.

I4 Encuesta realiza a una estudiante de I I años, en la ciudad de Barranquilla, febrero 2015. 
cuidarlo y no dejarlo tocar de nadie para que no nos pase nada" Otra estudiante 15: "El cuerpo es un templo de Dios, hay que hacerlo respetar y que nadie le falte el respeto". En este sentido, Beatriz Preciado ${ }^{16}$ afirma: la denominada programación de género, dada como una tecnología que parte de la premisa "un individuo = un cuerpo = un sexo = un género = una sexualidad". Ello garantiza "la relación estructural entre la producción de la identidad de género y la producción de ciertos órganos (en detrimento de otros) como órganos sexuales y reproductivos".

Los datos anteriores muestran que las y los estudiantes poseen un cuerpo natural y biológico. Por tanto, afianzado e inalterable en relación con las sexualidad reproductiva como condición necesaria. Esta razón, lo convierte en un cuerpo cuidado y protegido como un templo religioso solo para la procreación. Además, un cuerpo ubicado en la heterosexualidad. Es necesario superar esta visión biologizada y heterosexuada del cuerpo por la mirada integradora de cuerpo actuante, dinámico, cambiante y relacionado con un contexto sociocultural e histórico.

Esta visión biologicista construye cuerpos aconductados, ocultos, rígidos, y por tanto silenciados, sin contacto con el exterior del cual deben aislarse y protegerse para evitar el "peligro" de los dos graves factores que le acechan: el embarazo y la ITS. Es un cuerpo dominado, estereotipado y heterosexual según la visión tradicional de los géneros, unos masculinos con mayor acción en espacio público y otros femeninos con mayor restricción en lo público. No es un cuerpo para el disfrute de la libertad como encuentro con el entorno, ni la plasticidad artística, ni deportiva y otras como forma de fluir en el espacio y el territorio del cual emerge y actúa como actor social y en permanente cambio. En palabras de un estudiante ${ }^{17}$, "El cuerpo es lo que más se usa en el exterior para bailar, hacer deporte y jugar" y mientras que una estudiante ${ }^{18}$, "El cuerpo no se debe dejar tocar de nadie, es un templo". Esta mirada de género sobre el cuerpo, indica las distintas maneras como hombres y mujeres perciben y exteriorizan su cuerpo en el espacio público. En esta dirección, David Le Breton ${ }^{19}$, plantea que el cuerpo es como una ficción, pero una ficción culturalmente operante, viva. Igualmente, Judith Butler ${ }^{20}$, afirma que los cuerpos dentro del rango "normal" son culturalmente inteligibles como masculinos o femeninos, pero las reglas para vivir como varón o como mujer son estrictas. Es decir, que el aconductamiento de los cuerpos se efectúa en relación con lo que la cultura de dominación masculina y judeocristiana ha estipulado para lo masculino y lo femenino y excluyendo a las otras opciones sexuales. Preciado21, afirma: "La certeza de ser hombre o mujer es una ficción somaticapolítica producida por un conjunto de tecnologías de domesticación del cuerpo".

15 Encuesta realiza a una estudiante de 16 años, en la ciudad de Barranquilla, marzo 2015

16 Preciado, Beatriz. Testo Yonqui. Madrid: Espasa-Calpe, 2008, pág. 90.

17 Encuesta realiza a un estudiante de 16 años, en la ciudad de Barranquilla, marzo 2015

I8 Encuesta realiza a una estudiante de 14 años, en la ciudad de Barranquilla, febrero 2015

19 Le Breton. Op. Cit., pág. 33.

20 Anne Fausto-Sterling. Traducción de Ambrosio García Leal, Cuerpos sexuados, La Política de género y la construcción de la sexualidad, Ed. Melusina, Santa Cruz de Tenerife, 2006, pág. 99.

21 Preciado. Op. Cit., 2008, pág. 89. 
De esta manera, la educación sexual que recibe la población estudiantil, según lo muestran los resultados de las encuestas, vulneran su dignidad humana y varios de sus derechos humanos, entre ellos el derecho a la obligatoriedad a recibir una educación sexual eficiente de acuerdo con las necesidades psíquicas, físicas y afectivas y según su edad; el derecho al libre desarrollo de la personalidad; la libre asociación y elección erótica afectiva con información científica suficiente; el derecho a la educación para la sexualidad; el derecho a la construcción de ciudadanía y el derecho a la sexualidad alejada de lo reproductivo.

En el mismo sentido, el decreto reglamentario 1860 del 3 de agosto de 1994 establece en el Artículo 36 que: "la enseñanza prevista en el Artículo I4, se cumplirá bajo la modalidad de proyectos pedagógicos. La intensidad horaria y la duración de los proyectos se definirán en el respectivo plan de estudios Igualmente, se ratifican una educación sexual en marco de los derechos sexuales y los derechos reproductivos, que propone: "el derecho a información completa, científica y laica sobre la sexualidad". Esta normativa vigente, según los resultados de las encuestas no se cumple. Por tanto hay violación a este derecho humano.

Lo expresado por la población estudiantil en las encuestas, señala la vulneración al derecho a la educación sexual efectiva, como la ruta requerida para asumir el postulado de la Unesco (20 l0): la autorresponsabilidad de "sus propios actos" y comportamientos consigo misma y el reconocimiento de la otredad en la inclusión. De esta forma, se aleja la educación sexual en las escuelas de la misión inicial de la prevención del control natal, las ITS y los órganos sexuales masculinos y femeninos.

Se infiere entonces que es una educación sexual tradicionalista y a veces contradictoria. Solo se reconoce la sexualidad desde lo reproductivo y el cuerpo como un ente de órganos y funciones dispuesto para la procreación, en particular el femenino. No se plantea una sexualidad placentera Solo un cuerpo que hay que cuidar para garantizar la reproducción de la especie (embarazo). Se contradice cuando el embarazo se presenta como un peligro y un cuerpo que no debe ser acariciado como acto sublime de la sensibilidad humana en la afectividad, lo erótico y el encuentro permanente humano. ¿Cómo se comparte el goce de la afectividad y lo erótico a través de las caricias, si se insiste desde la pubertad que el cuerpo no debe ser tocado por nadie porque es un "templo de Dios"?

Por consiguiente, es necesario incluir tanto la sexualidad como el cuerpo en el contexto de las nuevas dinámicas sociales, normativas y corrientes teóricas. Al respecto Anthony Giddens ${ }^{22}$ señala: "la sexualidad plástica, la sexualidad descentrada, liberada de las necesidades de la reproducción". Esto coincide con lo que plantean los derechos sexuales y los derechos reproductivos. Igualmente, Butler ${ }^{23}$ afirma que la "materia" del cuerpo, no solo es un "sitio" o "superficie" receptor de cultura, es el producto de "un proceso de materialización" regulado por relaciones de poder que ordenan las significaciones en torno a lo "femenino" y lo "masculino". También, Preciado 24 manifiesta: "En

22 Giddens, Anthony. La Transformación de la Intimidad, sexualidad, amor y erotismo en las sociedades modernas. Madrid: Cátedra, 2008, pág. 12.

23 Butler, Judith. Cuerpos que importan, Buenos Aires: Paidós, 2005, pág. 28.

24 Preciado, Beatriz. Manifiesto contrasexual. Op. Cit., pág. 13. 
el marco del contrato contrasexual, los cuerpos se reconocen a sí mismos no como hombres o mujeres sino como cuerpos hablantes, y reconocen a los otros como cuerpos hablantes". También, Alain. Touraine, expresa: "La sexualidad no se reduce ni a una forma de consumo, ni a un erotismo "divino" que es su opuesto; es un llamamiento del individuo a sí mismo, a su libre creación, a su placer, a su felicidad"25

En tal sentido, se requiere que la comunidad estudiantil reciba un enfoque integral sobre la sexualidad y el cuerpo desde una mirada equitativa de género. Esto no solo incluye los aspectos de la prevención del control natal, las infecciones de trasmisión sexual, el cuerpo como un sistema de órganos y funciones y vinculado con los cambios del desarrollo evolutivo humano. También, las funciones emocionales, comunicativas, placenteras y eróticas de la sexualidad; que defina el cuerpo como territorio donde se tranversaliza todo el hacer y lo emocional del sentir del mundo de la vida humana, desde una perspectiva de género y de las distintas identidades de orientación sexual. Es según lo afirma Michel Foucault (2003) sacarla de debajo de las sábanas de la alcoba de las parejas conyugales y el confesionario donde estaba confiscada.

Se debe iniciar desde la infancia a nombrar las partes del cuerpo que incluya el espacio de lo "íntimo" o "privado" (órganos sexuales) enseñándoles a llamarlos por sus nombres correctos (pene, vagina, testículo y otros). Esto permite adquirir un léxico apropiado para conocer mejor su cuerpo desde la niñez y evitar nombrar los genitales por las mil maneras que la cultura popular ha determinado para seguir encubriéndolos en el silencio y el morbo que los han convertido en tabú.

Igualmente, se requiere que la escuela se apropie de la educación sexual y el cuerpo desde una perspectiva de género y de diversidad sexual, planificándolo como parte del currículo, estrategias pedagógicas eficientes y acordes a los nuevos métodos de enseñanza. No dejarlo para que sea tratado en forma ocasional por asignaturas distintas al tema y/o por visitantes extraños a la institución. Esto debe ser impartido por personas con experticias en la temática, que le den el enfoque requerido y contenido afín a la normativa vigente y los avances teóricos modernos. Además, la responsabilidad necesaria para el desarrollo integral, los requerimientos del desarrollo humano y el ejercicio de la ciudanía plena, como derecho humano que no se debe violar.

La responsabilidad de la escuela frente a la educación sexual implica reflexionar, comprender y dar a conocer que existen diversas formas de vivir y expresar la sexualidad humana. Esta es infinita y diversa porque cada persona siente el amor, el placer, la afectividad y lo erótico en relación con su propio contexto y realidad, ya sea individual o colectiva. En este sentido, en 2006 la Organización Mundial de la Salud (OMS) señala, en el desarrollo de la sexualidad interactúan factores "biológicos, psicológicos, sociales, económicos, políticos, culturales, éticos, legales, históricos, religiosos y espirituales". Por tanto las relaciones de amor o placer entre los seres humanos son tan variadas como tantas personas existen. Hay que aplicar en la escuela un currículo tanto explicito como implícito sin ningún tipo de exclusión, en especial de la diversidad sexual.

25 Touraine, Alain. ¿Podemos vivir juntos?. México: Fondo de Cultura Económica, 2006, pág. 69. 
También, la escuela debe eliminar el uso del lenguaje sexista. Que el androcentrismo y el heterosexismo no sean la fuente de inspiración para nombrar las cosas y los hechos de la vida cotidiana. Se requiere de un lenguaje reflexivo y crítico que genere formas equitativas e incluyentes que en el lenguaje no existía. Esto impide seguir legitimando la desigualdad en la construcción y trasmisión del conocimiento no inclusivo y, por tanto, violatorio de los derechos humanos y de la dignidad humana con equidad de género y justicia social inclusiva.

La educación sexual en la escuela debe superar la concepción binaria que relaciona mujer/ naturaleza y hombre/ cultura. Preciado ${ }^{26}$, señala "la heterosexualidad es una tecnología social y no un origen natural". Por tanto, es deconstruir esta visión sistemática que naturaliza y por tanto, ata cuerpos sexualidad en masculinos y femeninos, esta división tangencial de uno y otra, es un control social que limita su realización plena como sujeto de placer. La misma Preciado ${ }^{27}$ expresa: "de todos los cuerpos sujeto hablantes que se comprometen con los términos del contrato contrasexual dedicado a la búsqueda del placer saber". Es decir, que la educación sexual en la escuela debe ser garante para que las nuevas generaciones disfruten su sexualidad plástica como sujetos de derechos y deberes con autoresponsabilidad y reconocimiento de la otredad acorde a las nuevas exigencias del devenir histórico, la normativa jurídica y las corrientes teóricas.

\section{Conclusiones}

En la escuela, pese a los avances de las dinámicas sociales y del bloque constitucionalista que promulgan la equidad de género, aún persiste la reproducción del sistema tradicional y contradictorio de los roles de género masculinos, femeninos y heterosexual para el abordaje de la educación sexual y el cuerpo: Ello acentúa las homofobias y la vulneración de los derechos humanos, tanto de la población educativa en general, como la diversidad sexual en particular, junto con los otros grupos sociales que no encajen en el parámetro de lo que socialmente se ha construido como "normal".

La escuela como agente clave para la socialización de las nuevas generaciones, tiene la responsabilidad social y cultural de formar en la equidad de género y la inclusión, sin exclusión de ningún tipo para evitar los distintos tipos de violencias que se configuran en la escuela, tales como bullying, el acoso sexual y otros.

La importancia de la educación sexual en la formación del educando debe ser tema preferencial, planificado y científico desde el preescolar hasta la secundaria, con el fin de entregar una instrucción coherente y necesaria en cada etapa de la vida escolar. De esta forma, la población estudiantil puede aplicar su autoresponsabilidad de los derechos sexuales y los derechos reproductivos como parte de su proyecto de vida integral.

26 Preciado. Op. Cit., 20 I I, pág. 23.
27 . Ibid., pág. I3. 
La escuela, como ente socializante puede y debe construir espacios para hacer de la educación sexual y el cuerpo, desde la perspectiva de género un conocimiento sistemático, cuidadoso, científico y de fácil acceso que incluya a toda la comunidad educativa.

El cuerpo sexuado se construye y se utiliza durante todo el ciclo de la vida humana. Por tanto, debe reconocerse la autonomía del cuerpo personal y el de la otredad pero excluyéndolos de la visión tradicional de lo heterosexual, macho viril versus hembra, silueta y homosexual subordinados.

La obligatoriedad de la educación sexual en la escuela exige a que el género, la sexualidad y el cuerpo sean abordados sin estereotipos o arquetipos como la base objetiva y necesaria del discurso pedagógico inclusivo e integral de la ciudadanía plena y el reconocimiento de los derechos humanos. De esta manera, se supera la estrecha visión desde lo biologizante, hetero-reproductivo, biomédico y medicalizado de prevención del embarazo y las infecciones de trasmisión sexual como eje de la educación sexual en la escuela.

La sexualidad como derecho que se efectúa en el cuerpo, el cual es depositario de los distintos sentires humanos. Este deben ser resignificados desde una mirada de género como hecho y como espacio para la búsqueda de la felicidad plena. La felicidad debe plantearse como uno de los derechos humanos más sublimes y evolucionados de la humanidad.

\section{Bibliografía}

Anne Fausto-Sterling. Cuerpos sexuados, La Política de género y la construcción de la sexualidad, Ed. Melusina, Santa Cruz de Tenerife, 2006.

Butler, Judith. Cuerpos que importan, Buenos Aires: Paidós, 2005.

El género en disputa, Barcelona: Paidós, 2007.

Bourdieu, Pierre. Meditaciones pascalianas, Barcelona: Anagrama, 1999.

------- La dominación masculina, Quinta edición. Barcelona: Anagrama, 2005.

Connel, Robert. W. "Masculinidades". Programa Universitario de Estudios de Género. México: Universidad Autónoma de México, 2003.

Encuestas a la población estudiantil en el nivel de secundaria, residente en Barranquilla, en el ciclo de edades II a I8 años, Distrito de Barranquilla febrero a marzo 2015.

García, Carlos. Diversidad Sexual En La Escuela - Dinámicas Pedagógicas Para Enfrentar La Homofobia. Bogotá: Colombia Diversa, 2007.

Giddens, Anthony. La Transformación de la Intimidad, sexualidad, amor y erotismo en las sociedades modernas. Madrid: Cátedra, 2008. 
Fernández, Josefina. Cuerpos desobedientes. Travestismo e identidad de género. Buenos Aires: EDHASA-IDAES, 2004.

MEN - Ministerio de Educación Nacional, Estándares básicos de competencias en lenguaje, matemáticas, ciencias y ciudadanas, Bogotá 2006a.

-------- Proyecto piloto de educación para la sexualidad y construcción de ciudadanía: hacia la formación de una política pública, Bogotá, $2006 b$.

Morgade, Graciela; Alonso, Graciela. Educación, sexualidades, géneros: tradiciones teóricas y experiencias disponibles en un campo en construcción. En: (Comps.). Cuerpos y sexualidades en la escuela. Buenos Aires: Paidós, 2008.

Lagarde, Marcela. El cautiverio de las mujeres: madreesposa, monjas y locas. México: UNAM, 2003.

Le Breton, David. La sociología del cuerpo. Buenos Aires: Ediciones Nueva Visión, 2002.

- Testo Yonqui, Espasa-Calpe, Madrid. 2008.

-------. Manifiesto contrasexual. Barcelona: Amagrama, 201 I.

Touraine, Alain. ¿Podemos vivir juntos?. México: Fondo de Cultura Económica, 2006.

Serres, Michel. Variaciones sobre el cuerpo. . Buenos Aires: Fondo de Cultura Económica, 201 I.

SEN, Amarthy. Desarrollo como Libertad. Madrid: Planeta, 2000.

Weeks, Jeffrey. Sexualidad. México: Paidós, 2000.

Zolbrod, A. P. Sexo inteligente. Barcelona, España: Paidós 2000. 